\title{
Importance of patient compliance in small renal mass active surveillance
}

\author{
Paul Robert Martin, MD; Patrick P.W. Luke, MD, FRCSC \\ Schulich School of Medicine, University of Western Ontario, Division of Urology, Department of Surgery, London, ON
}

Cite as: Can Urol Assoc J 2012;6(1):15. http://dx.doi.org/10.5489/cuaj.11199

$A$ n 81-year-old man was found to have a 2.5 $\times 2.4 \times 2.0 \mathrm{~cm}$ right renal mass during hematuria evaluation using computerized tomographic (CT) scan of the abdomen in 2007 (Fig. 1, panel A, arrow). The patient was placed in a multicentre active surveillance trial. ${ }^{1}$ Pathologic examination of the small renal mass (SRM) biopsy was inconclusive and not repeated. A year later, the mass expanded to $3.0 \times 2.5 \times 2.0 \mathrm{~cm}$ (Fig. 1, panel B, arrow). However, the patient withdrew from the trial and was lost to follow-up.

In 2010, a repeat CT scan performed to investigate gross hematuria demonstrated that the mass grew to $7.0 \times 7.0 \times 6.5 \mathrm{~cm}$ (Fig. 1, panel C, arrow), with tumour thrombus extension into the inferior vena cava to the right atrium (Fig. 1, panel D, arrow). The patient underwent radical nephrectomy and caval thrombectomy. The pathology

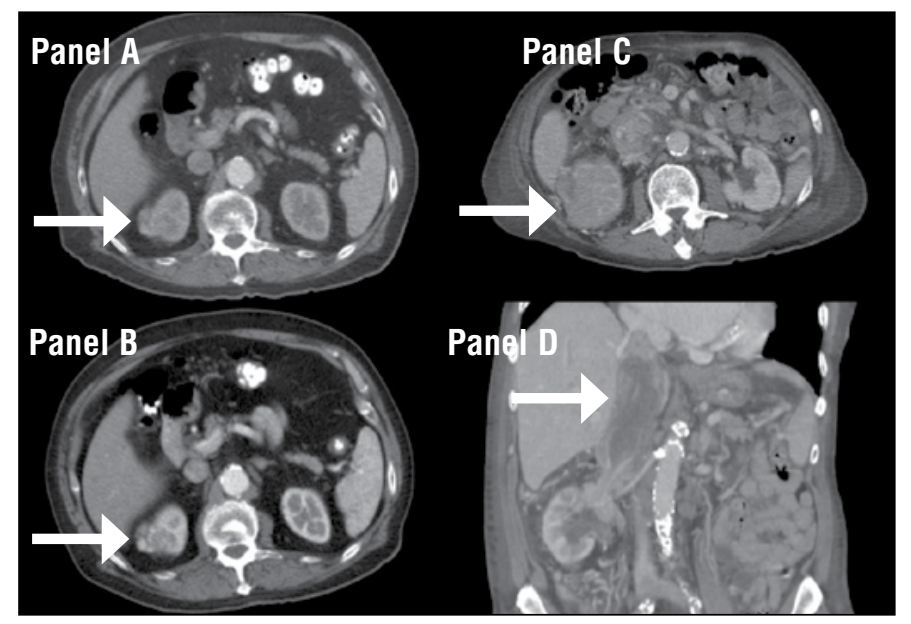

Fig. 1. A: Image of the $2.5 \times 2.4 \times 2.0 \mathrm{~cm}$ right renal mass (2007); B: A year later (2008), image of the expanded mass to $3.0 \times 2.5 \times 2.0 \mathrm{~cm}$; C: Image of the mass expanded to $7.0 \times 7.0 \times 6.5 \mathrm{~cm}$ (2010); D: 2010 tumour thrombus extension into the inferior vena cava to the right atrium. report disclosed Fuhrman grade 3 clear cell renal cell carcinoma, negative margins and negative nodes. Nine months postoperatively, the patient developed pulmonary metastasis.

Although active surveillance of a SRM is considered an appropriate strategy for patients with significant comorbidity or with short life expectancy, compliance to surveillance is paramount. This case illustrates how delaying immediate resection in lieu of active surveillance may lead to significant progression as a result of non-compliance.

Competing interests: None declared.

This paper has been peer-reviewed.

\section{References}

1. Jewett MA, Mattar K, Basiuk J, et al, Active surveillance of small renal masses: progression patterns of early stage kidney cancer. Eur Urol 2011;60:39-44. htrp://dx.doi.org/10.1016/i.eururo.2011.03.030

2. Campbell $S C$, Novick $A C$, Belldegrun A, et al. Guideline for management of the clinical $\mathrm{Tl}$ renal mass. J Urol 2009;182:1271-9. http://dx.doi.org/10.1016/i.juro.2009.07.004

Correspondence: Dr. Patrick P.W. Luke, London Health Sciences Centre, University Campus, 339 Windermere Rd, London, 0N N6A 5A5; fax: 519-663-3858; patrick.luke@lhsc.on.ca 